\title{
Narconovela colombiana: narrativa de corte thanático
}

Adriana Sara Jastrzębska

Universidad de Bielsko-Biała

"Colombia ostenta la paradójica condición de ser a la vez un país violento y un país culto" - observa Gustavo Cobo Borda, intelectual colombiano. ${ }^{1}$ La violencia en este país no sólo ha sido uno de los temas literarios más recurrentes, sino también una fuerza motriz del desarrollo de la literatura nacional que ha ido madurando en lucha perpetua entre lo culto y lo bárbaro en la identidad colectiva colombiana. Por lo tanto, la muerte igualmente es un motivo frecuente - si no inevitable - de toda novela que se proponga representar e interpretar la realidad histórica del país. De ahí que, Pablo Dussán caracteriza la narrativa colombiana reciente como una literatura "de corte thanático". ${ }^{2}$ Este es igualmente el caso de la narconovela, denominada también narrativa del narcotráfico o narrativa de las drogas ${ }^{3}$ : una modalidad o subgénero novelesco en que el narcotrá-

1 Cobo Borda 2008: 88.

2 Dussán 2005.

3 Términos utilizados p. ej. por Oscar Osorio (2014), Luis Molina Lora (2011) o Margarita Jácome (2016). La última distingue claramente entre la narconovela y la novela del narcotráfico centrándo la diferencia entre ellas en la calidad de las obras (2016: 49). En realidad no existe una sola taxonomía de las representaciones (y expresiones) literarias del narcotráfico. Mientras "narrativa del narcotráfico" o "narrativa de las drogas" como categoría implica cierto valor descriptivo y neutro, el concepto de "narconovela" o "narconarrativa" conlleva mucha más controversia, debido a la fuerza del prefijo que "... a diferencia del adjetivo que determina un lugar concreto, (...) anuncia una ruta que va más allá de lo que se pretende describir, es una señal o guiño que se hace para trazar un trayecto" (Olvera 2013: 12). Según Luis Molina Lora (2011: 289) el prefijo "narco" implica cierta perspectiva criminalizadora. Ambos investigadores coinciden en 
fico, su cultura, su estética y sus consecuencias sociales, políticas y culturales se traducen en la configuración ética y estética del mundo representado. Uno de sus rasgos característicos de suma importancia son ecos del pensamiento mítico y/o premoderno que subyacen tras la visión de la narcoviolencia urbana moderna y repercuten en la imagen literaria de las actitudes, comportamientos y percepciones de los personajes vinculados al mundo narco.

En el presente estudio nos concentraremos en las representaciones de la muerte en narconovelas colombianas seleccionadas para observar la multidimensionalidad de este motivo recurrente y, en cierto sentido, constitutivo de la narconovela. Alegaremos ejemplos que demuestran que el carácter thanático de esta modalidad narrativa no solo se manifiesta en el nivel diegético de las obras, sino igualmente se observa en la propia gramática narrativa de las mismas.

\section{LA "SICARESCA": CRÓNICA DE UNA MUERTE ANUNCIADA}

La variante más conocida y la más estudiada de la narconovela colombiana es lo que se denomina - como propuso Héctor Abad Faciolince - la novela sicaresca. ${ }^{4}$ Narra la vida de los jóvenes asesinos a sueldo, reclutados de los barrios de la miseria, crecidos en la violencia y muertos antes de llegar a adultos. Mario Vargas Llosa advierte que:

Además de formar parte de la vida social y política de Colombia, los sicarios constituyen también, como los cowboys del Oeste norteamericano o los samurais japoneses, una mitología fraguada por la literatura, el cine, la música, el periodismo y la fantasía popular, de modo que, cuando se habla de ellos conviene advertir que se pisa ese delicioso y resbaladizo territorio, el preferido de los novelistas, donde se confunden ficción y realidad. ${ }^{5}$

Efectivamente, las novelas sicarescas más destacadas e internacionalmente reconocidas, La Virgen de los sicarios (1994) de Fernando Vallejo, Rosario Tijeras (1999) de Jorge Franco Ramos y Sangre ajena (2000) de Arturo Alape, al representar a los sicarios protagonistas recurren a una tensión entre la ficción

notar y exponer cierta carga comprometedora que supone el prefijo. En el presente trabajo optamos por usar deliberadamente el término de "narconovela", ya que interpretamos las obras en cuestión como un intento por parte de los escritores de captar los cambios culturales que el narcotráfico supone, trazar el trayecto de una sociedad y una cultura marcadas por el fenómeno y sus consecuencias y, al mismo tiempo, dar cuenta de la perspectiva criminalizadora que se está volviendo cada vez más mainstream.

4 Abad Faciolince 1994.

5 VARgas Llosa 1999. 
literaria y la realidad extratextual; además, tiñen a los personajes de tonos antirrealistas caracterizándolos a través de unas metáforas religiosas y proponiendo cierta mirada marcada por el pensamiento mítico. En tal configuración estética la muerte, inherente al "oficio" del sicario, desempeña un papel crucial.

En primer lugar, en la sicaresca colombiana la muerte llega a ser la principal razón de ser del relato; determina, motiva y estructura la propia situación enunciativa. Tanto Rosario Tijeras como La Virgen de los sicarios y Sangre ajena narran las historias respectivas de los sicarios desde la muerte.

Rosario Tijeras de Jorge Franco Ramos es la historia de un particular triángulo amoroso: dos muchachos de clase media alta se enamoran de la misma muchacha, Rosario, que trabaja como prostituta y sicaria en servicio de narcotraficantes. Conocemos a la protagonista cuando Antonio, el narrador, la lleva, gravemente herida, a un hospital y, mientras espera una noticia sobre su estado, reconstruye y relata varios años de su amistad/amor.

"Como a Rosario le pegaron un tiro a quemarropa mientras le daban un beso, confundió el dolor del amor con el de la muerte" - desde la primera frase de la novela se establece una situación enunciativa en que se (con)funden el amor y la muerte. Rosario, herida durante un beso, se sitúa entre Eros y Thanatos, definiéndose desde su cuerpo y su mortalidad. El narrador abre su relato, observando: "Aún moribunda se veía hermosa, fatalmente divina se desangraba cuando la entraron a cirugía", ${ }^{7}$ y al final, se dirige al cuerpo muerto de la muchacha: "Hasta la muerte te luce, Rosario Tijeras". ${ }^{8}$ A lo largo de la novela, el retrato de la sicaria igualmente se construye mientras ella está debatiéndose entre vida y muerte; Antonio la narra desde una intemporalidad simbolizada por el reloj de la pared del hospital parado en las cuatro y media de la mañana. La muerte constituye un marco compositivo en que se encierra la historia de la muchacha sicaria y crea una particular configuración temporal de la novela, dotando de este modo a la protagonista, Rosario Tijeras, de cierta dimensión sobrehumana y trascendente; tema a que volveremos más adelante.

Igualmente recurriendo a la primera persona gramatical de un narrador-alter ego del autor, La Virgen de los sicarios narra la historia de un viejo intelectual que, tras muchísimos años fuera de Colombia, regresa a su Medellín natal donde se involucra en una aventura amorosa con un adolescente, un sicario proveniente de las comunas de la ciudad. Acompañado de Alexis, Fernando recorre las calles e iglesias de la ciudad transformada por la violencia e intenta asumir la brutal actualidad medellinense. Al principio un frío observador, un flâneur, el narrador poco a poco se sumerge en el mundo de la violencia, aprendiendo sus

\footnotetext{
${ }^{6}$ Franco 2000: 3.

7 FRANCO 2000: 3.

${ }^{8}$ Franco 2000: 80.
} 
maneras de pensar, sus actitudes y, sobre todo, su lenguaje. La muerte atraviesa todos los aspectos de la historia narrada: el narrador llega a Colombia para morir; encuentra la ciudad de Medellín llena de violencia y salpicada de "muñecos" ("cadáveres" en el parlache - el argot de las comunas) asesinados con razón o sin razón, con gallinazos que merodean un potrero donde un cartel reza "Prohibido arrojar cadáveres". Los sicarios adolescentes de quienes se enamora - Alexis primero y después Wílmar - llevan la muerte prematura como seña de identidad y cuando Fernando narra la historia, ya están muertos. La muerte en la novela de Vallejo constituye un eje constructivo del mundo representado tanto en su dimensión temporal, espacial, como en la configuración de los personajes.

Sangre ajena (2000) de Arturo Alape es una confesión de un ex-sicario, Ramón Chatarra, que narra a un entrevistador - alter ego del propio autor - su vida desde la niñez en la extrema pobreza de Ciudad Bolívar, la posterior fuga de la casa y el viaje a Medellín junto con su hermano Nelson, la iniciación en el mundo del sicariato, hasta la muerte de Nelson; un hecho que empuja a Ramón a volver a Bogotá y buscarse una nueva manera de vivir, fuera del mundo del crimen organizado. La estructura narrativa de la obra se configura como una conversación larga de Ramón y su interlocutor, en que uno revive sus memorias y el otro indaga, haciendo preguntas, a veces provocativas, al mismo tiempo presentándole al lector la realidad en que actualmente vive el ex-sicario.

Pero, ¿existe algo como un ex-sicario? Lo que le dota al personaje de Sangre ajena de una dimensión extraordinaria es el hecho de que Ramón Chatarra es un sobreviviente que, a través de su historia, no sólo se caracteriza a sí mismo, sino sobre todo narra muerte ajena, la de Nelson, convirtiéndose en portavoz del que ya no puede dar su testimonio. Puesto que el muerto es el hermano del narrador, en la novela se establece un interesante juego de mismidad y otredad, de paralelismos y divergencias, dado que los papeles de los personajes resultan "intercambiables": a Nelson le ocurre lo que bien hubiera podido ocurrir a Ramoncito. Los sobrevivientes hablan, pues, en nombre de los muertos, pero al mismo tiempo hablan por sí mismos, construyendo de esta manera una suerte de representación ambigua.

Amén de determinar y estructurar la situación enunciativa y dar razón al relato mismo, la muerte aparece en las novelas como un significante ingrediente de la construcción de los personajes. Uno de los ejemplos hemos visto más arriba: la muerte de uno convierte a los dos hermanos en una pareja de dobles que, por un lado, corren suerte diferente, pero por el otro, por consiguiente resultan complementarios, dando así la voz al muerto con su hermano sobreviviente como una suerte de medium. 
En Rosario Tijeras, la identificación de la protagonista con la propia muerte constituye uno de los principales procedimientos de configuración del personaje de la sicaria, como lo vemos por ejemplo en este fragmento:

Cuando salí del «shock» después de saber que Rosario mataba a sangre fría, sentí una confianza y una seguridad inexplicables. Mi miedo a la muerte disminuyó, seguramente por andar con la muerte misma. - Yo me la imagino como una puta -así me la describió-, de minifalda, tacones rojos y manga sisa. - $\mathrm{Y}$ con ojos negros - le dije yo. - Como parecida a mí, ¿no cierto? No le molestaba parecérsele, ni encarnarla. Hubo una época en que se maquillaba la cara con una base blanca y se pintaba los labios y los ojos de negro y en sus párpados se ponía polvo morado, como si tuviera ojeras. Se vestía de negro, con guantes hasta los codos y del cuello se colgaba una cruz invertida. Fue por los días en que andaba encarretada con el satanismo. - El diablo es un bacán -decía. ${ }^{9}$

Fernando Vallejo, a su vez, construye a los personajes de los sicarios Alexis en particular - a partir de referencias religiosas. Logra de esta manera un efecto de mitificación y desmitificación simultáneas e inseparables del personaje en cuestión.

Alexis, sicario adolescente, se convierte en mano armada del narrador, poniendo en práctica sus numerosos odios y deseos de exterminación. Amante de noche y verdugo de día: en el muchacho confluyen Eros y Thanatos, sexo y violencia, como fue en el caso de Rosario Tijeras. En La Virgen de los sicarios, igualmente, la imagen del sicario emerge del discurso del narrador como una reconstrucción imaginativa fuertemente marcada por la subjetividad. Y como la subjetividad narrativa de Fernando basa en tonos escatológicos, religiosos, pasionarios y sacrílegos, la configuración del personaje del sicario parte de estas características. Fernando confiere a Alexis a la Maria Auxiliadora: "Virgencita niña, María Auxiliadora que te conozco desde mi infancia, (...), hazme un favor: Que este niño que ves rezándote, ante ti, a mi lado, que sea mi último y definitivo amor; que no lo traicione, que no me traicione, amén", ${ }^{10}$ pero no sabe ni le interesa saber qué le pediría Alexis a la Virgen, recurre a la opinión de los sociólogos, quitandole a su amante toda individualidad y convirtiendo en uno de la multitud, sin olvidar concluir con una alusión erudita a Dostoievsky.

¿Qué le pediría Alexis a la Virgen? Dicen los sociólogos que los sicarios le piden a María Auxiliadora que no les vaya a fallar, que les afine la puntería cuando disparen y que les salga bien el negocio. ¿Y cómo lo supieron? ¿Acaso son Dostoievsky o Dios padre para meterse en la mente

\footnotetext{
9 Franco 2000: 34.

${ }^{10}$ VAllejo 2002: 8.
} 
de otros? ¡No sabe uno lo que uno está pensando va a saber lo que piensan los demás! ${ }^{11}$

Así, el sicario aparece más como forma, figura plana, existente en un hic et nunc; pura acción privada de un trasfondo psicológico, motivación y finalidad. Tal objetivización permite al narrador configurarle al joven a su antojo en su imaginación y en su discurso. Así, Fernando le dota a Alexis de una dimensión sobrenatural. Alexis "no respondía a las leyes de este mundo", ${ }^{12}$ es "ángel de la guarda", ${ }^{13}$ el "angelito tenía la propiedad de desencadenarme todos mis demonios interiores", ${ }^{14}$ escribe como "escriben los ángeles que son demonios". ${ }^{15}$ Aparecen en el discurso del narrador numerosas referencias a la pureza, incontaminación, como si se tratara de un ser angelical e inocente. Sin embargo, cuando ejerce su poder de dar muerte, Alexis cambia:

Sin alias, sin apellido, con su solo nombre, Alexis era el Ángel Exterminador que había descendido sobre Medellín a acabar con su raza perversa. ${ }^{16}$

En la noche borracha de chicharras bajó el Ángel Exterminador, y a seis que bebían en una cantinucha que se prolongaba con sus mesas sobre la acera, de un tiro para cada uno en la frente les apagó la borrachera, la "rasca". ¿Y esta vez por qué? ¿Por qué razón? Por la simplísima razón de andar existiendo. ${ }^{17}$

Como vemos, el personaje del sicario se inscribe en el discurso quasi-religioso de Fernando, adquiriendo rasgos de un ser divino o semi-divino, portador de la justicia de Dios.

Al mismo tiempo, como desconocemos el pasado de Alexis y su trayectoria vital individual - como los desconoce Fernando - y como la falta de un futuro es inherente al oficio de sicario, el joven existe solo en un presente correspondiente al periodo en que es percibido o, mejor dicho, "usado" por el narrador. Tampoco decide su suerte, su agencia es aparente o realiza la voluntad de otros o es víctima de casualidad y caos, lo que lo asemeja otra vez a puro objeto, puro arma.

Cuando el Ángel Exterminador muere, de sus cenizas - como en una quasi-resurrección - surge un otro igual. Fernando, sufriendo por la muerte de Alexis, se consola con Wílmar, otro sicario de las comunas, que, salvo el

\footnotetext{
11 Vallejo 2002: 8.

12 Vallejo 2002: 9.

13 Vallejo 2002: 6.

14 Vallejo 2002: 15.

15 VAllejo 2002: 28.

16 VALLEJo 2002: 34.

17 VAllejo 2002: 43.
} 
nombre propio, no difiere nada de su precedente. Al caracterizarlo, el narrador repite las mismas frases, el desarrollo de su historia amorosa es igual a la con Alexis. Más adelante, Fernando descubre que Wílmar mató a Alexis, para vengarse de su hermano muerto de la mano de aquél. Pronto muere también el propio Wílmar matado desde una moto por otro sicario.

La pareja Alexis-Wílmar es muy interesante desde el punto de vista de la subversión de la estética realista, ya que ilustra tanto su potencial simbólico y mítico, como su condición de seres efímeros y sustituibles. En una de las últimas escenas, la del "anfiteatro" (la morgue), se observa cómo los Alexis y Wílmar muertos se van multiplicando, privados de cualquier elemento que marque su humanidad y los diferencie de simples objetos, productos o residuos de la violencia.

En resumen, en la sicaresca colombiana la muerte constituye un fundamento en que se constryuen los elementos cruciales del mundo representado los personajes de los sicarios en este caso - y al miso tiempo determina la situación enunciativa desde que dicho mundo - igual de atravesado por la muerte y la violencia - se narra.

\section{Pero sigo siendo el Rey: LA MUerte como Rito}

El narcotráfico y la violencia que éste conlleva, constituyen un nuevo tipo de conflicto, una guerra postpolítica y postideológica. Desde los años 80 del siglo pasado, el mundo narco ha ido generando también su propia modalidad cultural, la denominada narcocultura que es

... un producto de la modernidad capitalista: capital, máquinas y consumo; el cumplimiento popular del sueńo del mercado liberal: consumirás y serás libre. Pero es a su vez premodernidad: moral de compadrazgo, la ley de la lealtad al dueño de la tierra y lo religioso como inspiración ética: contracultura desde las lógicas de la identidad local que lucha contra el imperio del capital. Pero un asunto postmoderno: vivir el momento, consumir al máximo como modo de participar de la sociedad bienestar, gozar el presente sin reparar en nada: el mal está en otra parte llamada norte, los ricos, los políticos [...]. Sin perder lo arcaico se ingresa a la modernidad para significar posmoderno: todos los tiempos, todos los flujos, todas las felicidades del capital pero en moral de pasado y placeres de presente: ¡del futuro es mejor no esperar nada! ${ }^{18}$

18 RinCón 2013: 5-6. 
Al configurarse como un territorio simbólico en que confluyen - como en el aleph borgeano - el pasado, el presente y el futuro, la narcocultura ostenta su profundo arraigamiento en la mentalidad premoderna y el pensamiento mítico. Las representaciones literarias del narco que han surgido en Colombia dan cuenta de dicho arraigamiento $\mathrm{y}$, al mismo tiempo, echan mano a las estructuras del pensamiento mítico, creando una suerte del narcorrealismo mágico latinoamericano.

La religiosidad particular del narcomundo ${ }^{19}$ combinada con elementos del pensamiento mítico llevan a interpretar la violencia en términos míticos (como fuerza autotélica, destino, o fatalidad) y percibirla como una suerte de rito. Este aspecto de la dimensión mítica de la narconovela es el más ostensible en el universo magicorrealista de Leopardo al sol (1993) de Laura Restrepo. La historia de muertes y venganzas entre dos familias tiene sus raíces en una mentalidad tribal que determina tal acitud y ritualiza el ciclo de la violencia:

Nando Barragán camina por el desierto una docena de días y de noches sin detenerse ni para dormir ni para comer, con el cadáver de Adriano Monsalve al hombro. En el horizonte, a su derecha, ve aparecer doce amaneceres teñidos de rojo sangre y a su izquierda ve caer doce atardeceres del mismo color. Es un vía crucis el que padece en el reino soberano de la nada $[\ldots]$. El cadáver se conserva intacto durante la travesía. ${ }^{20}$

En estas circunstancias y en un entorno que evoca territorios de mitos fundacionales, Nando encuentra a un "viejo profeta dueño de verdades y experto en fatalismos" 21 que le impone una serie de reglas y mandamientos respecto al cumplimiento de la venganza:

Has desatado la guerra entre hermanos y esa guerra la heredarán tus hijos, y los hijos de tus hijos. [...] Entre nosotros la sangre se paga con sangre. Los Monsalve vengarán a su muerto, tú pagarás con tu vida, tus hermanos los Barraganes harán lo propio y la cadena no parará hasta el fin de los tiempos [...]. Hasta acá no llega juez, ni abogado, ni tribunal. [...] Nuestra única ley es la que escribe el viento en la arena y nuestra única justicia es la que se cobra por la propia mano. [...] — Barraganes y Monsalves no podrán seguir viviendo juntos [...]. Tendrán que abandonar la tierra donde nacieron y crecieron, donde están enterrados sus antepasados: serán expulsados del desierto. [...] Si matas a tu enemigo, deberás hacerlo con tu propia mano; nadie podrá hacerlo por ti. La pelea será de hombre a hombre, y no por encargo [...].

${ }^{19}$ Hemos comentado ese tema de manera más amplia en el artículo Dimensión mítica y ritual en las representaciones literarias del narco (véase: JASTRZĘBSKA 2014).

${ }^{20}$ RESTREPO 2001: 16.

${ }^{21}$ Restrepo 2001: 17. 
— ¿Cuándo podré vengar a mis muertos? [...].

- Solamente en las zetas: a las nueve noches de su muerte, el día que se cumpla un mes, o en el aniversario. En las zetas tus enemigos te estarán esperando, y no los sorprenderás desprevenidos. Cuando el muerto sea de ellos actuarás de la misma manera, y en las zetas tú también te defenderás, y a los tuyos, porque ellos vendrán.

[...]

- Dime cómo debo enterrar a mis muertos.

- Con su mejor ropa, puesta por la mano de quien más los quiso. Los colocarás boca abajo en el cajón, y al sacarlos de tu casa, sus pies deben ir hacia adelante.

- ¿Quién ganará esta guerra?

- La familia que extermine a todos los miembros varones de la otra. ${ }^{22}$

Amén de claras connotaciones bíblicas, observamos en el extenso ejemplo no sólo un profundo arraigo de la narcoviolencia en una mentalidad premoderna, sino al mismo tiempo el concepto del pecado original y sus consecuencias, el crimen fundacional detonante y determinante de la violencia y muertes posteriores.

La actitud fatalista frente a la violencia y el carácter thanático de la cultura colombiana y la narcocultura convierten la muerte en un espectáculo, una celebración y un rito de pasaje. Las representaciones literarias del mundo narco enfatizan el aspecto lúdico de celebraciones de la muerte, como si el goce de la vida transgrediera la frontera de la existencia humana. En Rosario Tijeras se relata el "paseo" tradicional de su hermano muerto: "Después de que lo mataron nos fuimos de rumba con él, lo llevamos a los sitios que más le gustaban, le pusimos su música, nos emborrachamos, nos embalamos, hicimos todo lo que a él le gustaba". ${ }^{23}$ Siguiendo la misma tendencia, en la novela Comandante $\mathrm{Pa}$ raíso (2002) de Gustavo Álvarez Gardeazábal aparece una descripción detallada del entierro de un traqueto (narcotraficante, piloto en este caso de un avión de transporte) que murió transportando droga:

Ni el Cristo resucitado, que había salido el día anterior en procesión, alcanzó la magnitud del sepelio de Golondrino. Su hermano [...] contrató los catorce elefantes del Circo Gasca para que marcharan abriendo el cortejo revestidos con los colorines de la más lujosa presentación. Detrás de ellos la banda de Julio Tambora tocando aires marciales y entre la música y el féretro el grupo de niñas de la escuelita de Fenicia [...], llevando un pabellón con 27 cintas blancas, verdes y rojas, que bajaban chispeantes de un gran muñeco del Tío Sam con los ojos vendados, representando cada uno de los años de vida del sacrificado piloto.

22 Restrepo 2001: 17-18.

23 Franco 2000: 94. 
La misa la cantaron los del polifónico de Cali. En el atrio, al pie de María Auxiliadora, estaban los mariachis de Popayán con sus 34 instrumentos y cuando llegaron con el cadáver a las puertas de los Olivos, El Charrito Negro, todo vestido de negro y oro entonaba el "Pero sigo siendo el rey". ${ }^{24}$

Celebrar la muerte como una fiesta, un espectáculo, revela un profundo convencimiento de que la muerte es continuación de la vida y se configura como un acto colectivo de autoafirmación del pueblo que se identifica con la actividad, actitud y el sistema de valores del narco.

\section{El animal cazado: la muerte de Pablo Escobar}

Dedicaremos la última parte del presente artículo a una de las muertes más importantes y más icónicas de la historia del narcotráfico: la muerte de Pablo Escobar en un tejado de Medellín el 3 de diciembre de 1993. Encontramos referencias, directas o indirectas, a este acontecimiento en dos novelas de nuestro corpus de narconovelas colombianas: Happy Birtday, capo (2008) de José Libardo Porras y El ruido de las cosas al caer (2011) de Juan Gabriel Vásquez ${ }^{25}$.

Happy Birthday, Capo abarca las últimas ocho horas de la vida del jefe del Cartel de Medellín. Escobar, encerrado en su escondite, celebra su último cumpleaños en la vigilia de su muerte, todavía ignorada por él, pero ya presentida. Igual como en algunas novelas del dictador, al narrar su historia, el Capo se sitúa en una modalidad espacio-temporal muy particular, como si existiera fuera del tiempo y del mundo. Sintiéndo el aliento de la muerte en su espalda, es como "un naufrago y (...) en su botellon de agua no más de unas gotas". ${ }^{26} \mathrm{Su}$ vida se narra en pretéritos indefinidos y pluscuamperfectos, como un periodo ya cerrado y lejano. Observa el mundo desde la ventana de su escondite, pero no forma parte del mismo y vive sus últimas horas en un tiempo casi detenido:

...consultó el reloj: 8:22. Llevaba tres horas levantado, sin embargo su vida no se había movido, como si ya hubiera muerto, como un barco que encallando buscara escapar del abismo: el tiempo estaba cojeando, avanzando a otra velocidad, con otra lentitud, o no avanzaba, era un cadáver. ${ }^{27}$

24 Állvarez GardeazÁbal 2002: 245.

25 Es muy discutible poner la etiqueta de narconovela a El ruido de las cosas al caer, sin embargo en nuestros estudios sobre la modalidad literaria en cuestión la percibimos como cierre del corpus, ya que combina los rasgos de la convención y poética narco con elementos que - recurriendo al mismo repertorio de recursos - los cuestionan.

26 PORRAS 2008: 10.

${ }^{27}$ PORRAS 2008: 158. 
La supuesta muerte del tiempo -y la supuesta muerte del capo - se anuncian ya desde el primer capítulo de la novela. La muerte cobra protagonismo:

El reloj, que por el peso le pareció que era de plomo, le dijo con su tic tac: „El tiempo ha muerto". El Capo escuchó: "Su tiempo ha muerto". ¿Debería mandar a Inés a conseguirle una mortaja y cuatro cirios? Se vio en un ataúd, las manos sobre el pecho, con dos algodones tétricos en el fondo de las narices, a merced de las moscas. Aunque había vivido con la muerte a sus órdenes más de veinte años, diciéndole adónde ir y cómo actuar, aun produciéndola y modelándola con sus manos, ella le pareció un esperpento: no un concepto o un estado sino un monstruo..$^{28}$

Las visiones de la muerte y las reflexiones sobre sus consecuencias se repiten a lo largo del relato, creando un ambiente en que la muerte, aunque todavía no ha llegado, ya es palpable, ya se presiente, ha aunciado su inminente llegada. Dado que el día de la muerte anunciada de Pablo es el día siguiente al de su cumpleaños, estamos en una temporalidad en que confluyen el inicio y el final de una vida, celebrados los dos por el protagonista ya consciente de que la fiesta de cumpleaños es al mismo tiempo una suerte de velorio. El protagonista de la novela está vacilando constantemente entre la vida y la muerte, como un ánima en pena. ${ }^{29}$

A lo largo de la novela, el mito del Capo y su poder, fuertemente señalado y planteado en las primera páginas se irá deconstruyendo o más bien cuestionando y negando. Aunque en su monólogo interior el protagonista reitera que su ejemplo "había probado que se podía salir del huco, había indicado a los demás el camino al lujo, la comodidad y el reconocimiento" y se ve como un Cristobal Colón ${ }^{30}$, aunque presume de "haber logrado que el mundo adviertiera la existencia de un paisito llamado Colombia, lo que hasta entonces no habían podido generaciones de cancilleres y embajadores" 31 , de hecho asistimos en la novela a un descenso del Capo a su propio infierno, a un proceso que, en sus propias palabras del protagonista, es un proceso de disolución cuya cúspide será su muerte. ${ }^{32} \mathrm{El}$ hombre se siente cada vez más inseguro, le parecen sospechosos los obreros de al lado, los basureros vistos por la ventana parecen espiarlo; hasta los objetos del cuarto se ponen a criticarlo. El espacio se está encogiendo a su alrededor. Su último guardaespaldas, Corozo, le siente lástima. Piensa: "El

28 PORRAS 2008: 23-24.

29 Esta modalidad temporal emparenta la novela de José Libardo Porras con varias obras maestras de la literatura hispanoamericana del siglo XX: Yo el Supremo, El otoño del Patriarca, Pedro Páramo, La fiesta del Chivo o La muerte de Artemio Cruz.

${ }^{30}$ Porras 2008: 94.

31 Porras 2008: 18.

32 PORRAS 2008: 96. 
lobo se había transformado en cordero. O en gallina. (...) Vio enano al Capo: era una exageración que ofrecieran esa recompensa por él. Dos mil quinientos millones." ${ }^{33}$ La debilidad de Pablo se debe en gran medida a la ausencia de su gente; la soledad lo hace débil, lo que demuestra que - a pesar de ser un culto a la persona - el narcotráfico es un juego en equipo.

El descenso desemboca en un fracaso definitivo que al final de la novela se expresa en dos planos: el corporal y el espiritual. En su desesperada fuga final, Pablo logra subir al tejado del edificio y ahí cae herido a muerte.

There he collapses, and his paunchy stomach spills onto the red tile from his too-tight shirt. Trophy pictures taken by his jubilant enemies freeze for eternity the brutal image of his bloodied, overweight body.

This is the end od Escobar and of an era of daring, caudillo-like Colombian narcos who openly defied the state.

La autora de la descripción alegada, Aldona Pobutsky arguye que en este caso, el cuerpo debe percibirse una manifestación visible de la soberanía. ${ }^{34} \mathrm{La}$ profanación del cadaver del Capo y la difusión de su imagen en los medios se convierte en un mensaje legible para todas las partes de esta guerra:

...uno de ellos [los policías] saltó al tejado por la ventana, se arrimó al difunto, se inclinó, lo escrutó, lo removió, le puso una bota en la espalda, levantó los brazos y, formando una $\mathrm{V}$ con los dedos índice y medio de cada mano, gritó: ¡Viva Colombia! (...)

A los ocho o diez minutos (...) llegaron más policías y hombres de civil, de seguro periodistas, detectives y metiches. Uno se acercó al Capo; ella lo vio sacar de un maletín algo, al parecer unas tijeras, sí, eran tijeras, pues se agachó a recortarle mechones del bigote y del cabello; vio que sacó una cámara, lo fotografió y se hizo fotografiar pisando al muerto como si acabara de clavar la bandera de Estados Unidos en el lomo de la luna $(\ldots)^{35}$

La testigo ocular de la escena es la sirvienta Inés -una representante del pueblo que idealizaba y mitificaba a Escobar - y es ella quien pronuncia (murmurando, lo que es otro indicio de insignificación) lo que podemos interpretar como un fracaso definitivo espiritual del Capo: "Aquí yace el Capo, un rey sin corona. ¿Qué pasará con la muerte de Capo? ¡Nada! Todo seguirá igual”. ${ }^{36}$

Vale la pena subrayar que José Libardo Porras contribuye a reforzar la leyenda de Pablo Escobar como héroe popular optando en su novela por una de las múltiples versiones de la muerte del capo. En Happy Birthday, capo el

\footnotetext{
33 PORRAS 2008: 163.

34 Pobutsky 2013: 184-185.

35 PORRAS 2008: 237-238.

36 PORRAS 2008: 240.
} 
criminal más famoso del mundo no es matado por un policía, ni por un militar, sino por un sicario de otro cartel. Tal decisión del escritor pone de manifiesto la debilidad del gobierno colombiano, la omnipresencia de corrupción y negocios turbios y parece afirmar la actitud de una total desconfianza a los políticos y funcionarios del Estado, lo que en la cultura popular y de masas se traduce hoy en día en la glorifiación de los bandidos e identificación - por lo menos parcial - con la narcocultura.

Paralelamente, señala en la parte final de la novela ciertos mecanismos que irán construyendo y reforzando la leyenda de Pablo Escobar y la fama de la imagen de su cuerpo muerto fotografiado como un animal cazado, un trofeo:

John Morrison saltaba y manoteaba de felicidad. Con esa pieza elevaba su colección a una altura que los colegas envidiarían. Pondría al. Capo a la derecha de Abimael Guzmán, encima de Manuel Noriega. (...)

Continuaban llegando mirones. Unos no creían que el Capo hubiera muerto, otros temían que estuviera fingiendo o que ese cadáver fuera el de un impostor. ${ }^{37}$

La misma imagen del cadáver y su cazador triunfante en una foto publicada en la prensa constituye el punto de arranque de la novela El ruido de las cosas al caer. El narrador, profesor de Derecho Antonio Yammara, ve una foto y lee en una revista importante una noticia sobre un hipopótamo prófugo del zoológico de la Hacienda Nápoles matado con dos tiros por francotiradores que posaron con el cuerpo muerto.

Esta imagen lo hace recordar los últimos años del siglo pasado cuando, por casualidad, resultó herido durante un ataque en que murió su compañero de billar, un tal Ricardo Laverde. Recuperándose de la herida y sus graves consecuencias físicas y psíquicas, Yammara intenta reconstruir la historia de Laverde y descubrir el porqué de su asesinato en plena calle bogotana.

Para Aníbal González, el hipopótamo "deviene en un complejo símbolo que evoca fenómenos, como la globalización y el narcotráfico, así como la fiereza de un animal salvaje corpulento y torpe - como lo fue también su dueño, Escobar- . De hecho, la escena de la caza del hipopótamo a principios de la novela y la foto que se toman los cazadores junto al animal muerto evoca una foto grotescamente parecida que se tomaron los soldados del coronel Hugo Martínez alrededor del cadáver de Pablo Escobar en 1993. ${ }^{38}$ Es interesante que a la salida de la Hacienda Nápoles, los protagonistas también topan con un hipopótamo; escena que Alberto Fonseca interpreta como "recordatorio de lo que

37 PoRras 2008: 240.

38 GonZÁLEZ 2016: 471. 
todavía queda del pasado y de la discusión que todavía hoy existe en Colombia sobre lo que debemos hacer con la historia del narcotráfico." ${ }^{39}$

Efectivamente, a diferencia de otras obras mencionadas en el artículo, El ruido de las cosas al caer se concentra en las secuelas del narcotráfico "a largo plazo", opera desde cierta perspectiva que puede considerarse histórica y plantea el narcoterrorismo como un fenómeno ya cerrado, perteneciente al pasado, aunque vivo y vigente en los recuerdos y los traumas de los colombianos.

La movida mediática provocada por la muerte del animal prófugo, sirve como introducción y desentonador del relato que culmina con la visita de Antonio Yammara acompañado por la hija de Laverde en lo que queda de la Hacienda Nápoles. La más conocida de las propiedades de Pablo Escobar en el imaginario colombiano y en El ruido de las cosas al caer aparece como "un monumento al poderío económico y a la excentricidad de la narcocultura. El espacio funciona como sinécdoque de los lugares ocupados por la cultura narco que transformaron violentamente la geografía nacional." ${ }^{40}$ La Hacienda Nápoles, en ausencia de su antiguo propietario, se configura como un símbolo visible y palpable del narcotráfico y cobra protagonismo indudable. Su valor simbólico es multidimensional: la Hacienda simboliza a Pablo Escobar, el impacto del narcotráfico y la narcocultura en la realidad colombiana y, como destino de excursiones domingueras al legendario zoológico de familias con niños, la complicidad de los colombianos que, seducidos por el lugar, hacen vista gorda de la actividad criminal de su amo. El lugar se configura, pues, como un mito desmitificado, demostrando de esta manera, el fracaso del narcotráfico como una vía del éxito individual y/o colectivo.

\section{A MOdo De CONClusión}

El inventario de las funciones de la muerte en la gramática narrativa de las narconovelas colombianas seleccionadas nos lleva a las siguientes conclusiones:

La narconovela colombiana y, dentro de la categoría, la "sicaresca", indudablemente constituyen un ejemplo de narrativa de corte thanático. La muerte no sólo cobra protagonismo en el universo diegético de las obras respectivas, sino igualmente contribuye a configurar la gramática narrativa de los mundos representados y los principales "parámetros" del relato.

La muerte o un debatimiento entre vida y muerte sirven como impulso para iniciar el relato, justificarlo y estructurarlo. Se lo ve muy bien por ejemplo

39 FonseCa 2015: 88.

${ }^{40}$ Henao Uribe 2018: 167. 
en Rosario Tijeras donde el narrador recuerda su relación con la sicaria mientras espera en un hospital las noticias sobre la muchacha operada. De vez en cuando interrumpe su retrospección para volver a señalar al lector cuál es la situación enunciativa y subrayar el fluir de tiempo tan lento que parece detenido. En El ruido de las cosas al caer la noticia sobre la muerte del hipopótamo desentona en la memoria del narrador la historia de los años noventa y, al mismo tiempo, contribuye a crear una estructura circular del relato que culmina en un viaje a la Hacienda Nápoles donde los protagonistas topan con otro hipopótamo. Igualmente, en Leopardo al sol, es la muerte y la necesidad de repetirla en actos de venganza lo que estructura el relato sobre las familias de Barragán y Monsalve y determina el ritmo narrativo.

En esta novela vemos también que la presencia de la muerte y ritos relacionados con la misma permiten contextualizar la narconovela dentro del pensamiento arcaico y/o mítico que - combinado de manera estrafalaria con la tecnología hipermoderna y símbolos de poder económico - da origen a la llamada narcocultura. En Rosario Tijeras y Comandante Paraíso se representan las costumbres y ritos funerarios que hacen pensar en el concepto de la muerte como una particular prolongación de la vida.

Finalmente, en la tercera parte del artículo, presentamos la dimensión icónica de la muerte; en este caso la de Pablo Escobar representada en Happy Birthday, capo y aludida en El ruido de las cosas al caer. La muerte registrada en una fotografía se convierte en un símbolo, en una sinécdoque de una época entera y al mismo tiempo en toda una historia sobre un ascenso rápido y una inevitable caída.

El presente recorrido ofrece algunos de los numerosos ejemplos del protagonismo de la muerte tanto en la diégesis, como en la gramática narrativa de las narconovelas. Igualmente, dicho protagonismo hace que la narconovela constituya un interesante campo de estudios de índole psicológica, sociológica o estudios culturales y antropológicos.

\section{Obras ANALIZADAS}

Alape 2000 - A. Alape, Sangre ajena, Bogotá: Seix Barral 2000.

Álvarez Gardeazábal 2002 - G. Álvarez Gardeazábal, Comandante Paraíso, Bogotá: Grijalbo 2002.

Franco 2000 [1999] - J. Franco Ramos, Rosario Tijeras, Barcelona: Mondadori 2000. 
Porras 2008 - J. L. Porras, Happy Birthday, capo, Bogotá: Planeta 2008.

RestrePo 2001 [1993] - L. Restrepo, Leopardo al sol, Barcelona: Anagrama 2001.

VAllejo 2002 [1994] - F. Vallejo, La Virgen de los sicarios, Bogotá: Alfaguara 2002.

VÁSQUEz 2011 - J. G. Vásquez, El ruido de las cosas al caer, Bogotá: Alfaguara 2011.

\section{Bibliografía}

Abad Faciolince 1994 - H. Abad Faciolince, Lo último de la sicaresca antioqueña, "El tiempo" 5 (1994).

Сово Borda 2008 - J. G. Cobo Borda, El olvidado arte de leer, Bogotá: Taurus, 2008.

Dussán 2005 - P. García Dussán. La narrativa colombiana: una literatura thanática, "Espéculo: Revista de Estudios Literarios" 31 (2005).

FonseCa 2015 - A. Fonseca, Revisitando la Hacienda Nápoles: Las ruinas del narcotráfico en El ruido de las cosas al caer (2011) de Juan Gabriel Vásquez, en: C. López Badano (comp.), Periferias de la narcocracia. Ensayos sobre narrativas contemporáneas, Buenos Aires: Corregidor 2015, pp. 79-91.

González 2016 - A. González, Entrando en materia: novela, poesía y cultura material en El ruido de las cosas al caer. "Cuadernos de literatura" n. 20 (40), 2016, pp. 465-477.

Henao Uribe 2018 - L. Henao Uribe, Cartografias de violencia: centros, provincias y circulación transnacional en El ruido de las cosas al caer, de Juan Gabriel Vásquez, "Estudios de Literatura Colombiana", 42 (2018), pp. 157-173.

JÁCOME 2016 - M. Jácome. ¿Narco-novela o novela del narcotráfico?: apuntes sobre el caso colombiano, en: B. Adriaensen, M. Kunz (eds.), Narcoficciones en México y Colombia. Madrid: Iberoamericana 2016, pp. 27-52.

JASTRZĘBSKa 2014 - A. S. Jastrzębska, Dimensión mítica y ritual en las representaciones literarias del narco. "Romanica Silesiana", 9 (2014), pp. 78-87. 
Molina Lora 2011 - L. E. Molina Lora, Narrativa de drogas: una investigación transatlántica en la producción cultural de España, México y Colombia. Diss. Université d'Ottawa/University of Ottawa, 2011.

OlVERA 2013 - R. G. Olvera, Sólo las cruces quedaron: Literatura y narcotráfico, México: Ficticia Editorial 2013.

Osorio 2014 - O. Osorio, El narcotráfico en la novela colombiana, Calí: Programa Editorial UNIVALLE 2014.

Pobutsky 2013 - A. B. Pobutsky, Peddling Pablo: Escobar's Cultural Renaissance, "Hispania", 2013, pp. 684-699.

RINCóN 2013 - O. Rincón, Todos llevamos un narco adentro-un ensayo sobre la narco/cultura/telenovela como modo de entrada a la modernidad. "Matrizes", 7.2 (2013), pp. 1-33.

VARGas Llosa 1999 - M. Vargas Llosa, Los sicarios, "La Nación”, 5 (1999).

\section{Summary}

Colombian narco novel: a Thanatotic narrative

This article comprises an inventory of the motif of death within the narrative syntax of several Colombian narco novels. "Sicaresca" novels by Fernando Vallejo, Jorge Franco and Arturo Alape will be discussed. The construct of the characters, young contract killers, whose violent and premature deaths are seen as their fate, will be shown to display an indisputably "Thanatotic" facet. In the second part of this article, the ritual dimension of death, presented in the novels "Comandante Paraíso" by Gustavo Álvarez Gardeazábal and "Leopardo al sol" by Laura Restrepo, will be analysed. The last part will be dedicated to the iconic and symbolic dimension of Pablo Escobar's death depicted in "El ruido de las cosas al caer" by Juan Gabriel Vásquez and "Happy birthday, capo" by José Libardo Porras.

Keywords: narconovela, sicaresca novel, Thanatotic narrative, death

\section{Streszczenie}

\section{Kolumbijska narkopowieść: proza tanatyczna}

Niniejszy artykuł stanowi swoisty przegląd zastosowań motywu śmierci w narracyjnej gramatyce wybranych kolumbijskich narkopowieści. Zostały tu omówione powieści należące do kategorii novela sicaresca (powieści Fernando Vallejo, Jorge Franco, Arturo Alape), niewątpliwie „tanatyczne” w sposobie 
ukształtowania postaci nastoletnich płatnych morderców, w których życiu gwałtowna, przedwczesna śmierć wydaje się nieuniknionym przeznaczeniem. W drugiej części tekstu został omówiony rytualny wymiar śmierci przedstawiony w powieściach Comandante Paraíso Gustava Álvareza Gardeazábala oraz Leopardo al sol („Lampart w słońcu”) Laura Restrepo. Ostatnia część artykułu jest poświęcona ikonicznemu i symbolicznemu wymiarowi literackich reprezentacji śmierci Pabla Escobara w El ruido de las cosas al caer („Hałas spadających rzeczy”) Juana Gabriela Vásqueza i Happy Birthday, capo José Libardo Porrasa.

Słowa kluczowe: narkopowieść, novela sicaresca, śmierć, powieść „tanatyczna” 